\title{
Large-Scale Geochemical Impacts of Groundwater Replenishment with Reclaimed Wastewater
}

\author{
HENNING PROMMER ${ }^{1,2^{*}}$, JING SUN ${ }^{1,2,3}$, DAVID \\ SCHAFER $^{1,2}$, SIMONE SEIBERT ${ }^{4}$, ADAM J SIADE ${ }^{1,2}$, JAMES \\ JAMIESON $^{1,2}$ AND SIMON HIGGINSON ${ }^{5}$ \\ ${ }^{1}$ School of Earth Sciences, UWA, Crawley, WA 6009, \\ Australia (*Henning.Prommer@csiro.au) \\ ${ }^{2}$ CSIRO Land and Water, Floreat, WA, Australia \\ ${ }^{3}$ Institute of Geochemistry, CAS, Guiyang 550081, China \\ ${ }^{4}$ Federal Institute of Georesources, Hannover, Germany \\ ${ }^{5}$ Water Corporation of Western Australia, Leederville, WA \\ 6007, Australia
}

In many arid or semiarid regions changes in rainfall patterns and an increasing water demand are driving the search for alternative water sources. In Perth, Western Australia, groundwater replenishment of deep, anoxic aquifers using reclaimed wastewater has been identified as an important water management option to amend current water supplies. From early feasibility studies to the recently started full-scale implementation and operation, geochemical and reactive transport modelling studies have been an integral part of deriving a comprehensive understanding of the coupled physcial and geochemical processes that control groundwater quality evolution during replenishment. Data collected by a detailed hydrogeological and geochemical characterisation, batch-scale experiments such as respirometer tests, and a 4year long field trial were available to allow the development and validation of a suit of numerical models. Pyrite oxidation by the oxygen and nitrate contained in the injectant has been identified as the most important mineral reaction, with proton buffering and siderite dissolution preventing acidification and any significant mobilisation of metals.

This presentation will illustrate the challenges and selected approaches of translating the detailed lab-scale and local-scale hydrogeochemical understanding into large-scale and longterm predictions of future groundwater quality evolution within the replenished aquifers. One of the key questions was to understand whether the prevailing natural aquifer buffering capacity will remain sufficiently sustainable to prevent groundwater acidification and to minimise the risk of metal mobilisation. Reactive transport modelling was used to assess how various injectant pretreatment options could be used to most effectively mitigate the risk of groundwater quality deterioration.

[1] Seibert et al. (2014) WRR, 50(12), 9463-9483

[2] Seibert et al. (2016) WRR, 52(5), 4003-4025.

[3] Schafer et al. (2020) Env. Sci. Technol. 